\title{
INFORMATIE OMTRENT DE HERKOMST EN DE \\ BESTEDING DER MIDDELEN IN HET JAARVERSLAG
}

\author{
door Drs. C. Zwagerman
}

1 De belangstelling voor belegging van spaargelden door particulieren in aandelen is na 1945 sterk toegenomen. De in vele landen voortdurende waardedaling van de koopkracht van het geld en de fiscaal gunstiger behandeling van koerswinsten dan van rente-inkomen zullen daarbij een rol hebben gespeeld alsmede de in de afgelopen jaren gestegen sociale zekerheid, waardoor grotere groepen particuliere beleggers tot de aankoop van een belegging met grotere fluctuaties in de waarde van de hoofdsom dan in obligaties durfden over te gaan. Daarnaast zijn ook levensverzekeringsmaatschappijen en pensioenfondsen een groter deel van de hun ter beschikking staande middelen in de risicodragende sfeer gaan beleggen. Het percentage van het vermogen dat in vastrentende waarden is belegd, daalde bij de zes grootste particuliere pensioenfondsen ') in ons land van $72,3 \%$ in 1963 naar $62,2 \%$ in 1967, terwijl terzelfdertijd het gezamenlijke totale vermogen steeg van $f$,5 naar $f$ 5,0 miljard. Deze verschuiving naar aandelen- en vastgoedbeleggingen heeft zich tot dusver voortgezet. ${ }^{2}$ )

De beoordeling van de gang van zaken en de toekomstmogelijkheden, die belangrijke factoren bij de prijsontwikkeling van aandelen zijn, eisen bestudering van de algemene economische ontwikkelingen en van die in de verschillende bedrijfstakken, alsmede van de prestaties van de ondernemingen. De verslaglegging van ondernemingen in een aantal landen, waaronder Nederland, is nog zeer summier, hetgeen het inzicht bemoeilijkt.

De ontwikkeling heeft geleid tot het vergroten van de eisen die aan de verslaglegging van open vennootschappen worden gesteld (b.v. Verenigde Staten van Noord-Amerika, Engeland, Duitsland, Frankrijk en ook Nederland zie Ontwerp Wet op de Jaarrekening). Er ontstond een nieuw beroep, dat van de Beleggingsanalist, die bovenbedoelde studies maakt te zamen met een beoordeling van de actuele situatie en de middellange- en lange-termijn perspectieven op de aandelenbeurs en op deze wijze de basis legt voor aan- en verkoop beslissingen.

2 Uit de bestudering van de gang van zaken van ondernemingen zoals weergegeven in jaarverslagen wil men kennen:

a. de resultatenontwikkeling;

b. de financiële kracht, m.a.w. het in staat zijn tot dividendbetaling, voldoening van schulden, de mogelijkheid tot interne, resp. de noodzaak van externe financiering van de vervangings- en expansie investeringen.

Bij het beoordelen van de resultaten stuitte men op de verschillende methoden van winstbepaling, ook bij ondernemingen in dezelfde bedrijfstak, het-

1) nl. die voor personeel van Philips, de Mijnen, Shell, Unilever, K.L.M., AKU.

2) Deze cijfers zijn ontleend aan een onderzoek ingesteld door Drs. F. H. Geevers, beleggingsanalist te Rotterdam. 
geen onderlinge vergelijking van prestaties bemoeilijkte. Het meest in het oog lopende verschil bij de winstbepaling was de gevolgde politiek ten aanzien van afschrijving op duurzame produktiemiddelen.

In de in 1961 verschenen „Accounting Research Study No. 2" ${ }^{3}$ ) getiteld "Cash flow analysis and the Funds Statement" van Perry Mason worden uitspraken aangehaald ${ }^{4}$ ) van Ward Gates (The Magazine of Wall Street and Business Analyst, 19 Nov. 1960):

,And lastly - and possibly most important - is the fact that the profit margin squeeze is artificial, because one of the most rapidly increasing cost items is depreciation charged off against the newly created facilities... In effect, corporate profits today are being understated as never before..."

en van Forbes in „Business and Finance”, 1 Jan. 1960, in gelijke zin.

De „Permanent Commission on Standardisation and Terminology" van de European Federation of Financial Analysts' Societies kwam in haar rapport van januari 1967 ,Enquiry in to Cash Flow" tot de conclusie ${ }^{5}$ ):

,Nevertheless it must be admitted that in a large number of cases the published figures for depreciation will not be calculated to meet the analyst's requirements. The rates of depreciation, and the formulae employed, do indeed vary widely... There may therefore be an important and irreductible uncertainty in the figure for the net earnings of a company and the trend of depreciation may remain a relevant consideration when judging the trend of earnings."

Om inzicht in de financiële positie te verkrijgen werd getracht te berekenen welke liquide middelen de onderneming ter beschikking kreeg en deze te vergelijken met de financiële verplichtingen.

De beide hierboven genoemde doelstellingen van de analyses ${ }^{6}$ ) hebben geleid tot het berekenen van de z.g. "Cash flow"7), in de meerderheid der gevallen bestaande uit de som van winst na belasting vóór winstverdeling en afschrijvingen op vaste activa (tantièmes worden in de regcl echter als bedrijfskosten aangemerkt).

Een vertaling in het Nederlands is niet aangetroffen; in jaarverslagen van Nederlandse ondernemingen wordt vrijwel uitsluitend de terminologie in de Engelse taal gebruikt ${ }^{8}$ ), naar wordt aangenomen omdat b.v. (inkomende) kasstroom de indruk van een veel ruimer begrip zou wekken.

De twee doelstellingen zouden tot verschillende uitgangspunten voor de in aanmerking te nemen winst kunnen leiden. Voor een inzicht in resultatenontwikkeling is winst vóór aftrek van dividenden als basis te motiveren; voor inzicht in de financiële kracht wordt verdedigd") dat de verplichtingen aan

3) Van het Amerikaanse Instituut van Certified Public Accountants.

4) P. Mason - pag. 8 en 9.

5) Blz. 12 van dit rapport.

6) Zie ook Enquiry into Cash Flow, pag. 9 en 10.

7) In het Duits „Innenfinanzierung" of "Selbstfinanzierung", in het Frans ,autofinancement".

8) In het jaarverslag over 1967 van N.V. Houthandel Pont wordt het begrip aangeduid als ,,concernbaten vóór afschrijvingen en reserveringen", in dat van Stoomvaart Mij. Oostzec als "winst voor afschrijvingen en reservering", terwijl in "Kerngetallen van Nederlandsc effecten", uitgave van de Amrobank, cijfers worden gegeven van ,winst + afschrijvingen".

9) Overwegend in Engeland; rapport Enquiry into Cash Flow 1967, pag. 6. 
anderen dan aandeelhouders worden nagekomen uit de winst na dividendbetaling.

Indien men de financiële kracht wil bepalen, dient m.i. het te betalen dividend als een onderdeel van de totale verplichtingen te worden gezien; bovendien kunnen de overige eisen ten aanzien van de liquiditeiten een dividenddeclaratie in de weg staan. Ten slotte is het werken met twee begrippen onder dezelfde naam verwarrend en de voorkeur moet daarom - wil men ,,cash flow" hanteren - naar winst vóór dividend uitgaan. De in een aantal gevallen toegepaste aftrek voor aandeel van derden in de winst waar het een geconsolideerde jaarrekening betreft met dochterondernemingen die niet volledig door de moedermaatschappij worden gehouden, kan om dezelfde overwegingen beter achterwege blijven.

Vermeld zij nog dat bijzondere winsten en verliezen in veel gevallen buiten beschouwing worden gelaten bij de berekening van de „cash flow”.

3 Het gebruik van de ,,cash flow" is mede ontstaan uit de grotere aandacht die de winsten hebben gekregen, hetgeen tot uitdrukking kwam in het hanteren van de koers/winstverhouding, waarbij de koers van een aandeel wordt gedeeld door de winst per aandeel. Wellicht speelden ook de moderne begrippen over vergelijking van ontvangsten- en uitgavenreeksen - tot uitdrukking komend in ,discounted cash flow" (D.C. F.) berekeningen - een rol.

De vraag is echter of de onder 2 genoemde doelstellingen, $\mathrm{nl}$. inzicht in resultatenontwikkeling en in de financiële kracht, door middel van de , cash flow"-cijfers worden bereikt.

Mason beantwoordt deze vragen ontkennend ${ }^{\prime 0}$ ) en m.i. terecht. Wil men de resultaten kennen, dan dienen afschrijvingen in aanmerking te worden genomen en het feit dat deze in veel gevallen niet op dezelfde wijze worden berekend, mag er niet toe leiden deze kostenfactor geheel te verwaarlozen. Is er duidelijk sprake van te hoge afschrijvingen onder invloed van fiscale mogelijkheden of tot vorming van stille reserves, dan is om tot een bruikbare trend te komen een hercalculatie van winst op haar plaats en correctie van het belastingcijfer, waar nodig, moet dan niet over het hoofd worden gezien. Naarmate een vollediger jaarrekening verplicht wordt, zullen deze berekeningen òf overbodig worden òf doeltreffender kunnen worden uitgevoerd.

Bezwaar bestaat ook tegen het opnemen van afschrijving als bron van kasmiddelen. Een grote of kleine afschrijving is geen aanwijzing voor meer of minder vermogen tot kasgeneratie. De post is slechts bedoeld om het kostenelement dat in de onderhavige periode geen kasuitgave betekent, uit te schakelen. En het is duidelijk dat men met het wegnemen van afschrijving niet volledig is; men denke b.v. aan verkopen onder verlening van leverancierskrediet, aan activering van onderhanden werk. Anderzijds kunnen op krediet grondstoffen worden gekocht. Zonder een verdergaande analyse, waaronder die van nodige investeringen in duurzame produktiemiddelen, zegt een ,,cash flow"-cijfer over de financiële kracht zeer weinig, en het gevaar van onjuiste conclusies is niet ondenkbaar.

10) P. Mason „Cash flow analysis and the Funds Statement", 1961, pag. 30.

$m a b$ blz. 78 
Als reactie op het niet altijd oordeelkundig gebruik heeft de „Accounting Principles Board" van het Amerikaans Instituut van CPA's in „Opinion No. 3" „The Statement of Source and Application of Funds" (October 1963) o.m. gesteld:

,Misleading implications can result from isolated statistics in annual reports of "cash flow" which are not placed in proper perspective to net income figures and to a complete analysis of source and application of funds. "Cash flow" and related terms should not be used in annual reports in such a way that the significance of net income is impaired, and „,cash earnings" or other terms with a similar connotation should be avoided. The Board regards computations of „, cash flow per share" as misleading since they ignore the impact of cash expenditures for renewal and replacement of facilities and tend to downgrade the significant economic statistics of ,earnings per share"."

Het bestuur van de Amerikaanse „Financial Analysts Federation” heeft in april 1964 deze aanbeveling overgenomen.

4 Het „cash flow"-begrip geeft slechts enkele elementen uit de gevolgde financieringswijze. In het jaarverslag wordt er het laatste decennium meer naar gestreefd een inzicht te geven in de gang van zaken voor zover het de commerciële kant betreft. Het financieringsbeleid is echter ook van belang en het is aan te bevelen dit in het jaarverslag aan de orde te stellen.

In 1961 heeft Prof. Dr. B. Pruyt gewezen op de wenselijkheid ,,inzicht in de stroomgrootheden" van de onderneming te geven. "') In de Verenigde Staten van Noord-Amerika was in 1961 volgens de studie van P. Mason (zie onder 2) in 190 van de 600 onderzochte jaarverslagen van grotere industriële ondernemingen ${ }^{12}$ ) een ,funds statement" opgenomen. In de Opinion No. 3 van de Accountancy Principles Board van het Amerikaanse Instituut van CPA's van oktober 1963 wordt o.m. gezegd:

„The Board believes that a statement of source and application of funds should be presented as supplementary information in financial reports. The inclusion of such information is not mandatory, and it is optional as to whether it should be covered in the report of the independent accountant."

Een overzicht van de herkomst en besteding der middelen ${ }^{13}$ ) kan een beeld verschaffen van de wijze waarop de onderneming in staat is geweest de voor de bedrijfsuitoefening en voor winstuitdeling benodigde middelen aan te trekken.

Het geeft bovendien, vooral indien meer jaren worden getoond, snel een goed inzicht in de wijze van ontwikkeling der onderneming.

Begin 1969 waren van circa 250 industriële en handelsondernemingen de aandelen op de Amsterdamse effectenbeurs genoteerd (de banken en verze-

11) „Herkomst en besteding der middelen van een onderneming”, De Naamloze Vennootschap, april 1961.

12) Opgenomen in „Accounting Trends and Techniques”, jaaruitgave van het AICPA.

13) In het algemeen werd deze omschrijving in de jaarverslagen gebruikt; de KLM spreekt van liquidit eitsverloop. 
keringsmaatschappijen dus buiten beschouwing gelaten). Van de 116 ondernemingen met een geplaatst kapitaal van meer dan $f 5$ miljoen is nagegaan of er de laatste vijf jaar meer aandacht is gegeven aan cijfers die inzicht in de herkomst en in de besteding der middelen kunnen geven. De jaarverslagen van 1963/1967 en, voor zover beschikbaar, 1968 ${ }^{14}$ ) dienden hiervoor als basis.

Het resultaat was:

$\begin{array}{llllll}1963 & \text { èn } & 1967 / 8 & \begin{array}{l}\text { cash flow cijfers } \\ \text { wel cash flow }\end{array} & 7 & 16 \\ 1963 & \begin{array}{l}\text { geen, } \\ \text { èn }\end{array} & 1967 / 8 & \begin{array}{l}1967 / 8 \\ \text { overzicht herkomst en } \\ \text { besteding der middelen } \\ \text { overzicht herkomst en } \\ \text { besteding der middelen }\end{array} & 5 & 4 \\ 1963 \text { geen gegevens } & 1967 / 8 & \begin{array}{l}\text { overzicht herkomst en } \\ \text { besteding der middelen } \\ \text { geen van beide gegevens }\end{array} & 76 & 2\end{array}$

terwijl in $1967 / 8$ zes ondernemingen die niet als zodanig in 1963 publiceerden, een cash flow cijfer opnamen.

Van de elf ondernemingen die in de onderzochte categorie gegevens over de herkomst en besteding der middelen opnamen, behoren er zes tot de groep internationale fondsen.

Van deze laatste geeft alleen Philips geen staat van herkomst en bestedingen, waarbij echter moet worden aangetekend dat de wijze van financiering en de voorziene ontwikkelingen in het verslag ruim aandacht krijgen.

Geconstateerd mag worden dat er vooruitgang is, doch tevens dat de ondernemingen die door cijferopstellingen inzicht in het beleid geven, ver in de minderheid zijn. In de tekst der jaarverslagen werd over dit onderwerp in het algemeen zeer weinig of niets opgenomen.

5 a. Het overzicht van de herkomst en besteding der middelen doet allereerst de vraag rijzen wat onder middelen dient te worden verstaan. Hieronder wordt in de Verenigde Staten van Noord-Amerika vaak het totale bedrijfskapitaal, nl. kas, voorraden, debiteuren minus crediteuren, begrepen. Dit heeft als bezwaar dat geen inzicht wordt gegeven in de mate waarin de voorraad en vorderingen door leverancierskrediet worden gefinancierd. Een eveneens gebruikt begrip is kas (incl. kasbeleggingen) min bankkrediet. Dan ziet men echter niet, in hoeverre van bankkrediet gebruik is gemaakt voor de dekking van de behoeften. Kas en kasbeleggingen als middelen beschouwen is te prefereren, mits dit niet inhoudt dat uitsluitend kastransacties in het overzicht worden betrokken.

Het verwerven van een andere onderneming tegen uitgifte van aandelen, het omzetten van schulden in eigen kapitaal, van preferente aandelen in gewone aandelen zijn bijvoorbeeld transacties die een onderdeel vormen van het financieringsbeleid en als zodanig hun plaats in het overzicht moeten

14) Het onderzoek vond plaats in mei 1969.

$m a b$ blz. 80 
hebben, ook al geschieden de transacties met gesloten beurzen. Het over de kas laten lopen van inhouding van winst (enerzijds als uitdeling, anderzijds als vermogensaantrekking) ${ }^{15}$ ) is m.i. niet aan te bevelen; er is hier geen sprake van een overeenkomst waarbij de prestaties van beide partijen in geld gemeten gelijk zijn. Er is wel een financieringsbeslissing, doch het effect daarvan is duidelijker tot uitdrukking te brengen door aan te geven welk bedrag van de totale winst wordt uitgekeerd.

b. De samenstelling van een overzicht van herkomst en besteding van middelen behoeft geen bijzondere moeilijkheden te geven, mits voldoende gegevens beschikbaar zijn over de mutaties op de activa- en passivarekeningen. Uitgangspunt is een vergelijking van de balansen op twee balansdata. Prof. Dr. B. Pruyt geeft in zijn artikel ${ }^{16}$ ) een voorbeeld.

Ten aanzien van de te tonen cijfers zal op een aantal punten een beslissing moeten worden genomen. Hiervoor (zie onder $5 a$ ) is reeds vermeld dat voor een volledig overzicht ook transacties die per saldo geen kasmutatie geven, opgenomen dienen te worden. Als eerste bron van herkomst wordt in de me este gevallen uitgegaan van de winst van het jaar, waarna de kosten die geen kasuitgaven hebben gevergd, worden bijgeteld. In het algemeen vallen hieronder afschrijvingen op duurzame produktiemiddelen en de vorming van voorzieningen of reserves voor bijzondere doeleinden. Deze posten zijn geen bron van ontvangsten; deze laatste worden niet direct ${ }^{17}$ ) beinvloed door de afschrijving en overige kosten, die geen uitgaven zijn. Een omschrijving zoals hierboven: „Kosten die geen uitgaven vergden”, is derhalve aan te bevelen. Indien de betaalde belasting in de loop van de periode een belangrijke afwijking toont van de ten laste van de winst gemaakte belastingvoorziening, is er reden de winst vóór winstbelasting op te nemen en de betaalde belasting afzonderlijk te vermelden.

Een andere mogelijkheid is het overzicht te doen beginnen met opbrengst van verkopen en daarvan de kosten die gelijkgesteld worden met uitgaven (grondstoffen, lonen en salarissen, reclamekosten e.d.) af te trekken. ${ }^{18}$ )

Het verband met de resultatenrekening gaat dan veelal verloren. In Nederland worden deze elementen van de winst- en verliesrekening vaak niet opgenome $n^{14}$ ), hetgeen deze wijze van opstelling in de weg staat. In de Amerikaanse jaarverslagen wordt dit deel van de herkomst der middelen dikwijls aangeduid als ,income from operations". In de Nederlandse jaarverslagen geschiedde deze onderindeling vrijwel niet, naar aangenomen wordt uit de overweging dat de winst ook na correctie voor kosten die geen uitgaven zijn, in geen van beide bovengenoemde vormen kasontvangsten behoeven te representeren. Afleveringen kunnen op krediet gedaan zijn, grondstoffen op krediet gekocht, terwijl er ook transitorische posten zijn. De nodige correcties komen uit de vergelijking van de betrokken activa- en passiva-rekeningen. c. Bij de vaste activa dienen verkopen van relatief belang niet gesaldeerd te

15) Prof. Dr. B. Pruyt, Herkomst en besteding der middelen, 1961.

16) Herkomst en besteding der middelen van een onderneming, 1961.

17) Wel indirect in zoverre de verkoopprijs door deze kosten beinvloed is.

18) B.v. N.V. Overzeese Gas- en Electr. Mij en in vroegere jaren N.V. Kon. Petroleum Mij.

19) In het wetsontwerp op de jaarrekening worden in art. 29 ook nog geen cijfers over omzet en primaire kosten - anders dan afschrijvingen - verlangd. 
worden met de investeringen. Deze desinvesteringen zullen als regel een incidenteel karakter dragen en het inzicht in de ontwikkeling van de investeringen wordt door saldering dan verstoord. Er is hier nog een nevenvraagstuk: eventuele winst of verlies op verkoop is begrepen in winst/verlies die als uitgangspunt van de berekening van de herkomst der middelen is genomen en men zou derhalve slechts de boekwaarde moeten opnemen. De totale opbrengst geeft echter een beter beeld en wordt veelal ook getoond, zij het dat de noodzakelijke aanpassing opgenomen zal zijn onder diverse posten. ${ }^{20}$ ) $d$. De mutaties in leningen op lange termijn zijn voor een goed inzicht te splitsen in nieuwe leningen en aflossingen op bestaande leningen. Het afzonderlijk opnemen van beide geeft in een overzicht van enige jaren een beeld van de druk der aflossingsverplichtingen enerzijds en van het totale bedrag der op lange termijn opgenomen middelen anderzijds.

e. De mutatie in het bedrijfskapitaal behalve kas - voorraden, debiteuren en crediteuren - wordt op verschillende wijzen behandeld. Men kan alle posten te zamen nemen ${ }^{21}$ ), dan wel alle afzonderlijk ${ }^{2}$ ) of een combinatie van voorraden en debiteuren met als afzonderlijke post de opgenomen leverancierskredieten. Indien de onderlinge verhouding van deze posten naar de usantie in de bedrijfstak vrij constant blijft, is de combinatie te verdedigen. Zodra leverancierskrediet, onder invloed van kostenafwegingen, een element wordt van het financieringsbeleid, is een aparte vermelding meer op zijn plaats. Hetzelfde geldt voor afnemerskrediet: een wijziging van het beleid te dien aanzien zal tot hogere of lagere debiteurencijfers aanleiding geven, die aparte vermelding rechtvaardigen. Een toelichting bij het overzicht is hierbij van belang.

f. De winstuitdeling kan een belangrijke invloed op het financieringsplan hebben. In een overzicht daarvan behoort die verdeling een plaats te vinden. In de praktijk ziet men daarbij verschillende methoden: als uitkering vermelden de bedragen die in het jaar zijn uitbetaald (en dan zullen stammen uit de winst van het voorafgaande jaar) ${ }^{23}$ ), of de uitkering over het jaar waarover verslag wordt uitgebracht onder de besteding der middelen opnemen. ${ }^{24}$ ) Deze laatste methode (met als tegenpost een verhoging van crediteuren voor uit te betalen dividenden, m.a.w. opnemen van kort krediet) heeft het voordeel dat in het jaaroverzicht direct verband bestaat tussen winst en verdeling daarvan. De eerste methode is meer afgestemd op het doel van het overzicht, nl. inzicht te geven in de kasmutaties van het jaar.

$6 \quad \mathrm{Bij}$ de geconsolideerde jaarrekening doen zich nog enkele bijzondere vragen voor. Indien in de loop van het verslagjaar een meerderheidsbelang in een andere onderneming is verworven, zullen de activa en passiva daarvan in de geconsolideerde jaarrekening over dat jaar zijn opgenomen. De verwerving van een dochteronderneming is in het algemeen van zodanig belang dat de

20) B.v. KLM, Unilever.

21) AKU, Hoogovens, Unilever.

22) Gist-Brocades, Texoprint.

23) B.v. Gist-Brocades, Koninklijke Zout Organon.

24) B.v. Overzeese Gas. 
uitgave daarvoor afzonderlijk is te vermelden. De mutaties op de geconsolideerde balanshoofden bevatten ook reeds het effect van het opnemen daarin van de verworven onderneming en dienen derhalve geëlimineerd te worden, voor zover zij betrekking hebben op de datum van verwerving. Hetzelfde geldt mutatis mutandis bij afstoting van een deelneming. Bij de internationale concerns is dit extra werk gezien de geringe relatieve invloed meestal niet verantwoord en zal de dubbeltelling die ontstaat door uit te gaan van balansmutaties onder een hoofd Overige Posten worden weggenomen. ${ }^{25}$ )

Ook kan het voorkomen dat een dochteronderneming eerst in een later jaar dan dat van de verwerving in de geconsolideerde jaarrekening wordt opgenomen. De mutaties uit de balansvergelijking geven ook in dit geval een onjuist financieringsbeeld. De beste oplossing zal zijn de cijfers aan het begin van het jaar op gelijke wijze te herzien (dus inclusief die van de nieuw geconsolideerde onderneming) en daarna het overzicht op te stellen. Indien dit niet mogelijk is, dient bij de mutaties berekend op basis van de twee niet geheel vergelijkbare posities aan het begin en aan het eind van het jaar een toelichting te worden gegeven - op de hoofden waar deze relatief van betekenis zijn - van de effecten van de gevolgde methode.

Indien er minderheidsbelangen bestaan in geconsolideerde ondernemingen aan wie dividend wordt uitbetaald, is het m.i. het meest consequent, uitgaande van de totale geconsolideerde winst, deze derden naast de aandeelhouders van de moedermaatschappij als tot die winst gerechtigden te beschouwen en de aan hen uitgekeerde bedragen als zodanig op te nemen. ${ }^{26}$ )

Verschillen kunnen eveneens ontstaan door waardewijzigingen van vreemde valuta, indien er buitenlandse dochterondernemingen zijn. Bij devaluatie bijvoorbeeld zal er een verlies ontstaan, waarvan de grootte mede afhankelijk is van de gevolgde waarderingsmethoden. Het vermelden van relatief belangrijke invloeden in de toelichting is dan noodzakelijk.

7 Systematiek in vorm bepleitte reeds Prof. Pruyt in zijn eerder genoemd artikel. Overzichten van meer jaren zijn aan te bevelen en hierdoor kan een opbouw die voor één jaar het meest doelmatig is, worden doorkruist door de wens voor een reeks van jaren eenzelfde indeling te geven. Goede informatie zou een opbouw als volgt geven:

25) B.v. Unilever.

26) B.v. Koninklijke Petroleum Mij., Overzeese Gas. 
Nettowinst ${ }^{2 \cdot}$ )

Kosten die geen uitgaven vergden (afschrijvingen)

Vrijgekomen uit

voorraden en handelsvorderingen ${ }^{28}$ )

opbrengst verkopen duurzame produktiemiddelen

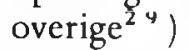

Aantrekking van middelen

op lange termijn: eigen vermogen

op korte termijn: $\quad$ bankkredieten ${ }^{31}$ )

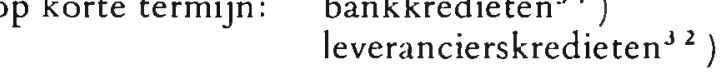
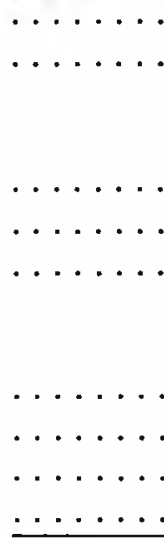

Totaal ter beschikking gekomen middelen

BESTEDING

Investeringen

belangen in andere ondernemingen

duurzame produktiemiddelen

voorraden en handelsvorderingen ${ }^{28}$ )

Aflossing van kredieten

op lange termijn

op korte termijn: bankkredieten ${ }^{3}$ ।)

leverancierskredieten ${ }^{32}$ )

Dividenden (incl. aan houders van minderheidsbelangen)

Overige posten ${ }^{3}$ )

Totaal bestede middelen

Saldo herkomst en besteding van middelen

Middelen aan het begin van het jaar

Middelen aan het eind van het jaar

27) Er kan aanleiding zijn de winst vóór belasting op te nemen; de betaalde belascing zal dan onder Besteding worden opgenomen (m.i. na Investeringen) - zie hiervoor onder 5 (b).

28) Zie hiervoor onder 5 (e).

29) Desinvesteringen, zoals afstoten belangen in andere ondernemingen.

30) Te splitsen (of in toelichting te vermelden) in opgenomen leningen, gevormde voorzieningen (b.v. voor pensioenrechten).

31) Bankkredieten te salderen.

32) Eventueel te combineren met mutatie op voorraden en han-

delsvorderingen - zie hiervoor onder 5 (c).

33) Toe te lichten indien van relaticve betekenis.

Eventucel onder Herkomst der middelen. 
8 Het verkrijgen van inzicht in de financiële positie wordt verbeterd door het opnemen van een overzicht van de ter beschikking gekomen en bestede financciële middelen. In het merendeel der gevallen kan niet worden volstaan met cijfers; een toelichting daarop is zeer gewenst.

Hierbij moet onmiddellijk worden aangetekend dat de feiten van het verleden niet voldoende zijn. Een goed inzicht in de financiële kracht krijgt men slechts indien ook aandacht wordt gegeven aan de verwachte toekomstige ontwikkeling en dit geldt uiteraard voor de gehele gang van zaken. Het jaarverslag is nog overwegend een stuk waarin rekenschap wordt afgelegd van gevoerd beheer over het afgelopen jaar, en slechts enkele ondernemingen geven enige indicatie over de verwachte ontwikkelingen.

In dit verband dient de aanbeveling van de Vereniging van Beleggingsanalisten te worden vermeld aan de Bijzondere Commissie van de Tweede Kamer der Staten-Generaal belast met de behandeling van het wetsontwerp op de jaarrekening. Tijdens de ,hearings" op 19 november $1968^{34}$ ) stelde de Vereniging voor, de jaarstukken van de onderneming tevens een „Directieverslag" te doen bevatten, waarin onder meer een "financieringsschema" opgenomen zou moeten worden, alsmede de investeringsplannen en de wijze waarop de onderneming denkt deze te financieren.

Het meer opnemen van een overzicht van herkomst en besteding der middelen dan tot nu toe zou reeds een stap vooruit zijn en aanknopingspunten geven voor de verwachte toekomstige situatie. Dit zou dan kunnen uitgroeien tot een hoofdstuk in het jaarverslag, getiteld „,Financieel beleid”.

34) Verslag van de Bijzondere Commissie d.d. 17 december 1968. 